\title{
Towards assessing the influence of sediment loading on Last Interglacial sea level
}

\author{
T. Pico ${ }^{1,2}$ \\ ${ }^{1}$ Department of Earth and Planetary Sciences, Harvard University, Cambridge, MA 02138, USA. E-mail: tpico@caltech.edu \\ ${ }^{2}$ Geological \& Planetary Sciences, Caltech, Pasadena, CA 91125, USA
}

Accepted 2019 October 3. Received 2019 September 25; in original form 2019 May 24

\begin{abstract}
SUMMAR Y
Locally, the elevation of last interglacial (LIG; $\sim 122 \mathrm{ka}$ ) sea level markers is modulated by processes of vertical displacement, such as tectonic uplift or glacial isostatic adjustment, and these processes must be accounted for in deriving estimates of global ice volumes from geological sea level records. The impact of sediment loading on LIG sea level markers is generally not accounted for in these corrections, as it is assumed that the impact is negligible except in extremely high depositional settings, such as the world's largest river deltas. Here we perform a generalized test to assess the extent to which sediment loading may impact global variability in the present-day elevation of LIG sea level markers. We numerically simulate river sediment deposition using a diffusive model that incorporates a migrating shoreline to construct a global history of sedimentation over the last glacial cycle. We then calculate sea level changes due to this sediment loading using a gravitationally self-consistent model of glacial isostatic adjustment, and compare these predictions to a global compilation of LIG sea level data. We perform a statistical analysis, which accounts for spatial autocorrelation, across a global compilation of 1287 LIG sea level markers. Though limited by uncertainties in the LIG sea level database and the precise history of river deposition, this analysis suggests there is not a statistically significant global signal of sediment loading in LIG sea level markers. Nevertheless, at sites where LIG sea level markers have been measured, local sea level predicted using our simulated sediment loading history is perturbed up to $16 \mathrm{~m}$. More generally, these predictions establish the relative sensitivity of different regions to sediment loading. Finally, we consider the implications of our results for estimates of tectonic uplift rates derived from LIG marine terraces; we predict that sediment loading causes 5-10 m of subsidence over the last glacial cycle at specific locations along active margin regions such as California and Barbados, where deriving long-term tectonic uplift rates from LIG shorelines is a common practice.
\end{abstract}

Key words: Loading of the Earth; Sea level change; Numerical modelling.

\section{INTRODUCTION}

Refining the magnitude of excess ice melting at the last interglacial (LIG; 122 ka Dutton \& Lambeck 2012) informs assessments of the stability of ice sheets in response to today's warming climate, and it relies on correcting sea level records for local processes of vertical displacement including tectonic uplift, dynamic topography and ice and ocean loading histories (i.e. Creveling et al. 2015; Austermann et al. 2017; Dendy et al. 2017). Sediment loading is one such process potentially contaminating the sea level record. While regional studies have shown sediment can influence sea level on glacial timescales (Simms et al. 2007, 2013; Wolstencroft et al. 2014; Ferrier et al. 2015, 2018; Pico et al. 2016), in this paper we pose the question globally: to what extent might sediment loading control the variability of LIG sea level observations, and where are these effects most substantial?

To answer these questions, we construct a global history of sedimentation over the last glacial cycle, and use a gravitationally selfconsistent model of glacial-isostatic adjustment (GIA) to predict sea level change as a result of sediment loading. We then compare our predictions to a global compilation of 1287 sea level observations using a robust linear regression model that accounts for spatial autocorrelation. We investigate whether there is a statistically significant relationship between our modelled sea level change and the elevation of sea level observations globally, or at passive or active tectonic margins. This analysis has implications for estimates of long-term uplift rates at tectonically active margins based on the elevation of LIG sea level highstands (e.g. Radtke et al. 2006; Muhs 
et al. 2012; Simms et al. 2016). Moreover, our results provide a framework for quantifying the extent to which sediment loading may impact previous estimates of peak globally averaged sea level during the LIG (Kopp et al. 2009, 2013). Future improvements in constraining the history of sedimentation, for example, by using observations such as sediment cores, can be readily input into this statistical framework.

\section{METHODS}

\section{Observations: LIG data set}

We use a database of 1753 measured elevations of LIG sea level markers (Fig. 1) used in Austermann et al. (2017). Where multiple measurements were made at a single location, we retain the peak value, which results in a final data set of 1287 observations. This global sea level database is compiled from previously published LIG sea level markers (Ferranti et al. 2006; Kopp et al. 2009; Pedoja et al. 2014; Hibbert et al. 2016), and includes markers on passive (354) and active (933) tectonic margins. We use the coral reef record of Hibbert et al. (2016), as interpreted in Austermann et al. (2017). Each marker is assigned an associated indicative meaning (as described in Austermann et al. 2017), and we explore the uncertainty associated with the interpretation of the sea level marker by running our analyses using both the upper and lower bounds reported in this database.

\section{Observations: tectonic uplift rates}

At active tectonic margins, palaeo sea level records are commonly used to derive estimates of long-term uplift or subsidence rates. As an example, a typical procedure uses marine terraces dated to the LIG to infer long-term tectonic uplift rates by considering the difference between the expected and observed elevation of the LIG sea level marker, and these rates are then adopted to correct for palaeo-shorelines dated to other periods (e.g. MIS 5a/5c, MIS 11, i.e. Chappell et al. 1996; Radtke et al. 2006). However, choosing a reference LIG sea level value is complicated by uncertainty in the magnitude and timing of peak GMSL, as well as the significant geographic variability in the elevation of LIG markers associated with local processes, such as GIA (Lambeck \& Chappell 2001; Creveling et al. 2015; Simms et al. 2016). An additional confounding factor contributing to variability in LIG shoreline elevations is the sea level change due to sediment loading. Since erosion rates often scale with uplift (Perron 2017), tectonically uplifting margins tend to produce high volumes of sediment, which are ultimately transported to the oceans. The impact of this mass flux may be important to consider when estimating the tectonic uplift rate of marine terraces.

To illustrate this issue, we compile LIG marine terrace data from Simms et al. (2015) and Radtke et al. (2006) and estimate the effect of sediment loading on estimates of long-term tectonic uplift rates in two regions: the North American west coast and Barbados.

\section{Modelling: glacial isostatic adjustment}

Sea level varies spatially in response to the redistribution of surface mass loads, including ice, water and sediment, as ice sheets grow and decay over a glacial cycle. We perform calculations based on the theory and pseudo-spectral algorithm described by Kendall et al. (2005) with a spherical harmonic truncation at degree and order
512. These calculations include the impact of load-induced Earth rotation changes on sea level (Milne \& Mitrovica 1996; Mitrovica et al. 2005), evolving shorelines and the migration of grounded, marine-based ice (Johnston 1993; Milne et al. 1999; Lambeck et al. 2003; Kendall et al. 2005), and they incorporate a gravitationally self-consistent treatment of sediment loads (Dalca et al. 2013; Pico et al. 2016).

Although sediment loading prior to the LIG would have induced an ongoing isostatic response at the LIG, we are interested in estimating sea level change since the LIG due to sediment load changes over only the last glacial cycle. Thus, we limit our modelling to the period from 122 to $0 \mathrm{ka}$ to assess the magnitude of sea level change due to sediment loading since $122 \mathrm{ka}$.

\section{Modelling: constructing global sedimentation history over the last glacial cycle}

In order to construct a sediment loading history since the LIG we adopt a global compilation of modern river flux measurements (776 rivers; total suspended sediment in post-dam measurements reported in Milliman \& Farnsworth 2011). River fluxes varied over the course of the glacial cycle. However, at present there is insufficient data on rivers globally to assess the time history of sediment delivery to the ocean for most rivers over the last glacial cycle. As a consequence, in this study we assume that sediment flux is uniform through time. Improving this model of sediment loading will require detailed studies of each river that incorporate erosional and depositional records over the last glacial cycle, including accumulation rates based on sediment cores (as in Ferrier et al. 2015; Pico et al. 2016).

We model the riverine sedimentation since the LIG by simulating marine river deposition using a diffusive model applied to the case of a migrating shoreline. We adopt shoreline predictions from a GIA simulation based on Earth model VM2 and the ice history ICEPC2 based on a suite of constraints on global ice volume histories during MIS 5a, 5c and MIS 3 (Pico et al. 2016; Dendy et al. 2017; Pico et al. 2017). The model is run with 200-yr time steps over $100000 \mathrm{yr}$; the river mouth (sediment flux source) evolves with the shoreline, the position of which is determined by searching for the nearest coastline node at every time step. Sediment deposition occurs solely in oceanic regions, as determined by the predicted shoreline location.

To simulate marine deposition, we adopt an alternating direction implicit (ADI) method for solving the diffusion equation, including the sediment flux as a source term and a diffusion constant of $1 \times 10^{6} \mathrm{~m}^{2} \mathrm{yr}^{-1}$ (Swenson 2005). This simple diffusive model has been used to simulate deltas dominated by bulk sediment transport, and does not include suspended sediment transport by waves or currents (Fagherazzi \& Overeem 2007). Deposition in deeper waters is not modelled, as estimates of the proportion of sediment transported to deeper ocean basins is not well-constrained over the last ice age, and this sedimentation will likely have minimal effects on sea level markers near modern coastlines.

The simulation approximates the broad scale geometry of sedimentation in which rivers with high sediment flux build large deltaic depocentres, while small rivers draining mountainous areas build a more diffusive region of deposition. To conserve mass, we uniformly remove a layer of sediment from each continental drainage basin with a volume equivalent to the sediment flux deposited in the oceans. This procedure accounts for the density difference between marine $\left(1750 \mathrm{~kg} \mathrm{~m}^{-3}\right)$ and terrestrial sediments $\left(2650 \mathrm{~kg} \mathrm{~m}^{-3}\right.$, Bahr 


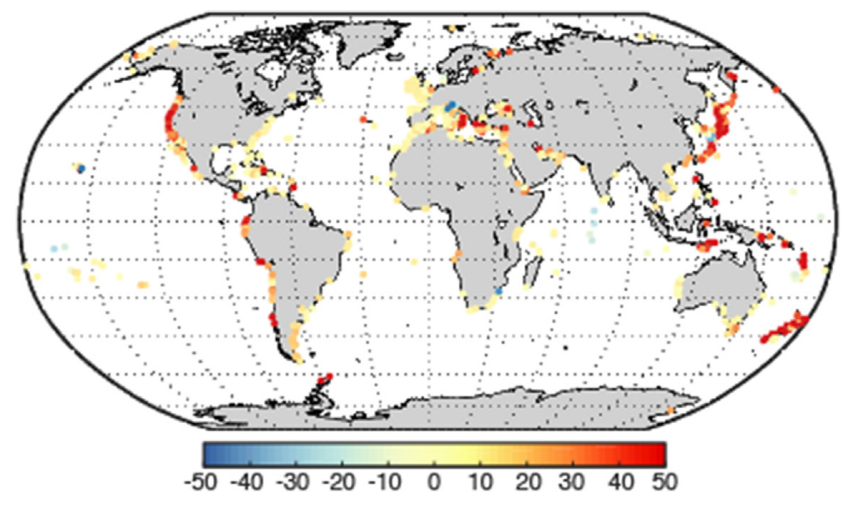

Figure 1. Elevation of last interglacial sea level markers at 1287 sites (see text).
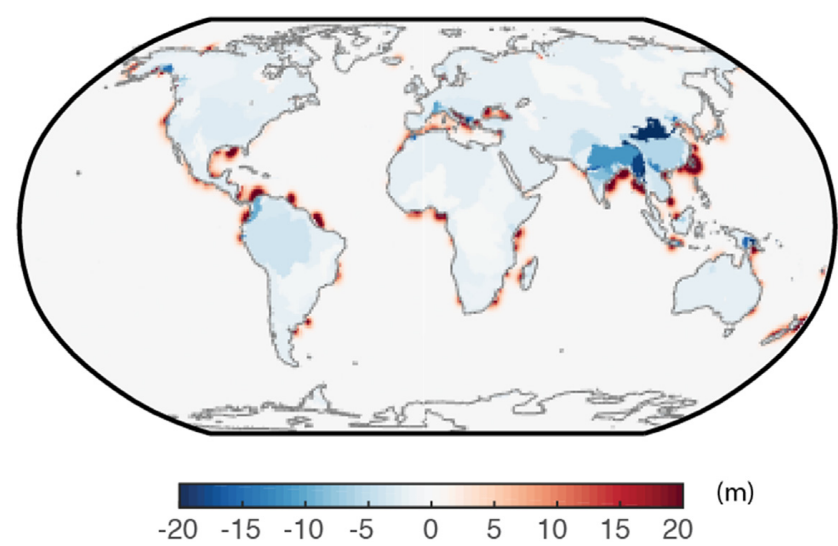

(m)

Figure 2. Cumulative modelled sediment transfer from 122 to $0 \mathrm{ka}$.

et al. 2001). The resulting sediment erosion and deposition over the last glacial cycle is shown in Fig. 2.

The diffusive model is clearly not valid for all rivers; for example, it does not include floodplain deposition, river avulsions, or differential on-land erosion rates, and therefore it cannot accurately capture the precise details of individual river depocentres. Nevertheless, these sediment loads are smaller or similar to the wavelength of lithospheric flexure $(\sim 100 \mathrm{~km})$, so the isostatic response to such loads will be minimal. Therefore, rather than reproducing the exact geometry and absolute magnitude of sea level change induced by sediment loading, we expect the modelled sea level change to be representative of the relative sensitivity of different regions to sediment loading,

\section{RES ULTS}

\section{Sea level response to sediment loading}

Using the reconstruction of sedimentation distribution described above, we derive a time-varying sediment loading history since the LIG. We then perform GIA simulations that adopt this history using earth model VM2 (as in shoreline calculation; Methods), and in this second step we ignore ice and ocean load changes in order to isolate the effect of sediment loading. However, we note that the impact of such ice and water loading changes are implicitly accounted for the in shoreline position, which controls the location of sedimentation in our model. We also note that our predictions account for water volume displacement through sediment deposition, but do not account for the effects of sediment compaction on changes in

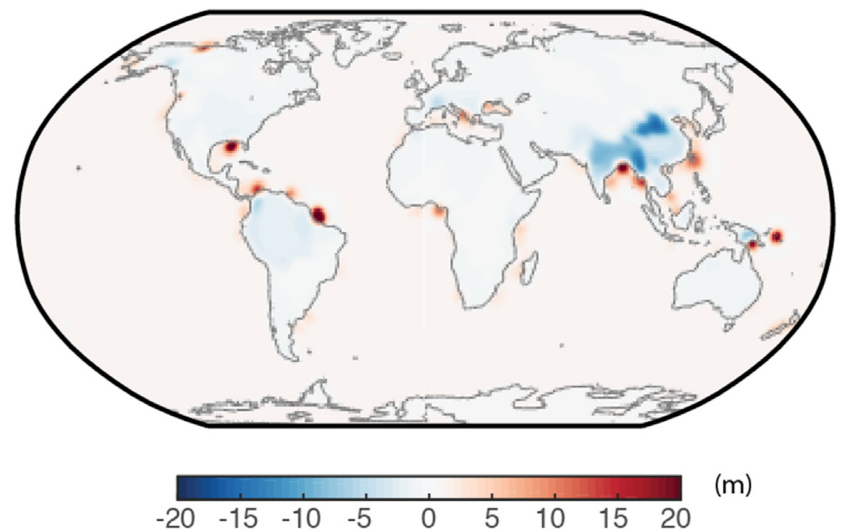

Figure 3. Modelled sea level change due to sediment loading from 122 to $0 \mathrm{ka}$ relative to the LIG. Positive values are areas where sediment loading has caused an increase in sea level since the LIG.

porewater volumes. The resulting sea level change due to sediment loading since the LIG is shown in Fig. 3.

Sites susceptible to sediment loading experience a sea level rise in response to this loading. Therefore, the present-day elevation of LIG sea level markers would be lower than one would predict in the absence of sediment loading (Fig. 4). We would then expect a negative correlation between predicted sea level change due to sediment loading and the elevation of LIG sea level markers.

The largest sediment loading sea level signals are located near major river deltas, and these sea level effects are highly localized ( $<\sim 100 \mathrm{~km}$ scale). However, sediment loading associated with small rivers that drain uplifting mountain ranges can also drive relatively large $(5-10 \mathrm{~m})$ sea level changes along active tectonic margins because high erosion rates in uplifting regions produce higher sediment fluxes. Clearly, future improvements in available constraints on sedimentation history will help to accurately estimate the regional impact of sediment loading on LIG sea level markers in terms of absolute magnitude and geometry.

\section{Statistical analysis}

We next explore whether predicted spatial variability of sea level changes due to sediment loading is reflected in the observed elevation of LIG sea level markers. LIG sea level markers sampled at different locations are not independent from each other, and thus we build a regression model that incorporates spatial autocorrelation. We account for whether a site is tectonically active, in addition to estimating the sea level change due to GIA associated with ice loading since the LIG (at $122 \mathrm{ka}$ ) to account for uncertainty in sea level marker elevation variability due to ice and ocean loading. We do not, however, apply tectonic corrections to the LIG sea level marker elevation, as this would introduce circularity since tectonic uplift rates are often derived from these data. To capture uncertainty on modelled GIA at the LIG we use an average value of a suite of earth models using an ice history that spans two ice-age cycles (see Appendix). Although our analysis in the main text is based on the predicted sea level change due to sediment loading using a single earth model, we also consider the sensitivity of this result to our earth model selection.

We first run a least squares regression model, $Y=\beta_{0}+$ $\beta_{1} X_{\mathrm{SLsed}}+\beta_{2} X_{\text {active }}+\beta_{3} X_{\mathrm{GIA}}+\beta_{4} X_{\text {interact }}+\varepsilon$, where $Y$ is the observed elevation of 1287 LIG sea level markers, and $X$ includes the following predictor variables: (1) a variable of the mean-centered 
(a) Last Interglacia

(b) Present-day without
sediment loading (c)
Present-day with sediment loading
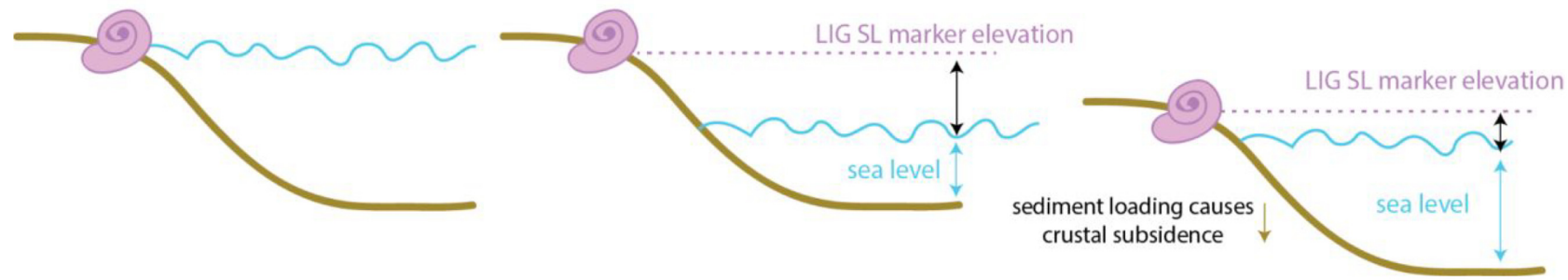

Figure 4. Schematic diagram shows (a) sea level at the LIG and the observed elevation of a LIG SL marker for a site (b) without sediment loading and (c) with sediment loading. The observed elevation would be lower at a site with high sediment loading because sea level change due to sediment loading from the LIG to present is dominated by local crustal subsidence (relative sea level rise).

predicted sea level change due to sediment loading ( $X_{\mathrm{SLsed}}$ calculated from Fig. 3); (2) a dummy (binary) variable that distinguishes between active and passive margin sites ( $\left.X_{\text {active }}\right)$, where active sites are assigned a value of one and passive sites are assigned a value of zero; (3) an interaction term $\left(X_{\text {interact }}\right)$ where active margin sites are set equal to $X_{\text {SLsed }}$, the predicted sea level change variable and (4) a GIA term that is calculated from the average of 70 earth models using a single ice loading history ( $X_{\mathrm{GIA}}$; see Appendix). The $\beta$ values represent the expected change in $Y$ for a unit change in each $X$ variable and $\varepsilon$ represents the error term.

We define an interaction term $\left(X_{\text {interact }}\right)$ to understand differences in the relationship between predicted sea level $\left(X_{\text {SLsed }}\right)$ and sea level marker elevation $(Y)$ for active sites versus passive sites. By setting $X_{\text {interact }}$ equal to the value of $X_{\text {SLsed }}$ at active margin sites and $X_{\text {interact }}$ equal to zero at passive margin sites, we can estimate the relationship between $Y$ and $X_{\text {SLsed }}$ for just active margin sites to understand how sediment loading effects may differ between passive and active margin sites.

In order to account for spatial autocorrelation, we calculate the residuals from this model and use these to construct an autocovariate variable $\left(X_{\mathrm{ac}}\right)$ that is a distance-weighted function of the neighboring response values. The distance range of neighbors is set by fitting a semivariogram to the residuals and calculating the range, which yields a value of $5.44 \mathrm{~km}$. Next, we use a linear model that uses MM-estimation to perform an analysis that is robust and resistant to outliers. We use MM-estimation because this method of parameter estimation in a regression model is not highly influenced by outliers (Susanti et al. 2014), and our data set has a large number of outliers. This model includes the above predictor variables ( $X_{\text {SLsed, }} X_{\text {active }}$ $\left.X_{\text {interact }} X_{\mathrm{GIA}}\right)$ and the autocovariate variable $X_{\mathrm{ac}}$, which accounts for spatial autocorrelation: $Y=\beta_{0}+\beta_{1} X_{\mathrm{SLsed}}+\beta_{2} X_{\text {active }}+\beta_{3} X_{\mathrm{GIA}}+$ $\beta_{4} X_{\text {autocovariate }}+\beta_{5} X_{\text {interact }}+\varepsilon$.

In Fig. 5, we plot the elevation of LIG sea level markers against the predicted sea level change due to sediment loading $\left(X_{\text {SLsed }}\right)$ for passive (blue) and active (pink) margins. The other predictor variables, such as $X_{\mathrm{GIA}}$, are included in the slope and intercept of the fitted line. The shaded regions in the figure represent the calculated error bars in the regression for passive and active margin sites. The estimated $\beta$ coefficients for each variable are shown in Table A1. As discussed in the context of Fig. 4, we expect a negative correlation to exist between the observations and the prediction. In the case of passive margins there is no clear relationship between the predicted signal from sediment loading and the elevation of sea level markers (slope $=-0.138 \pm 0.305 ; p=0.651$; Fig. 5). For active margins, there is a weak, yet significant, positive relationship (slope $=1.169 \pm 0.739 ; p=3.72 \times 10^{-14}$ ) between the two.

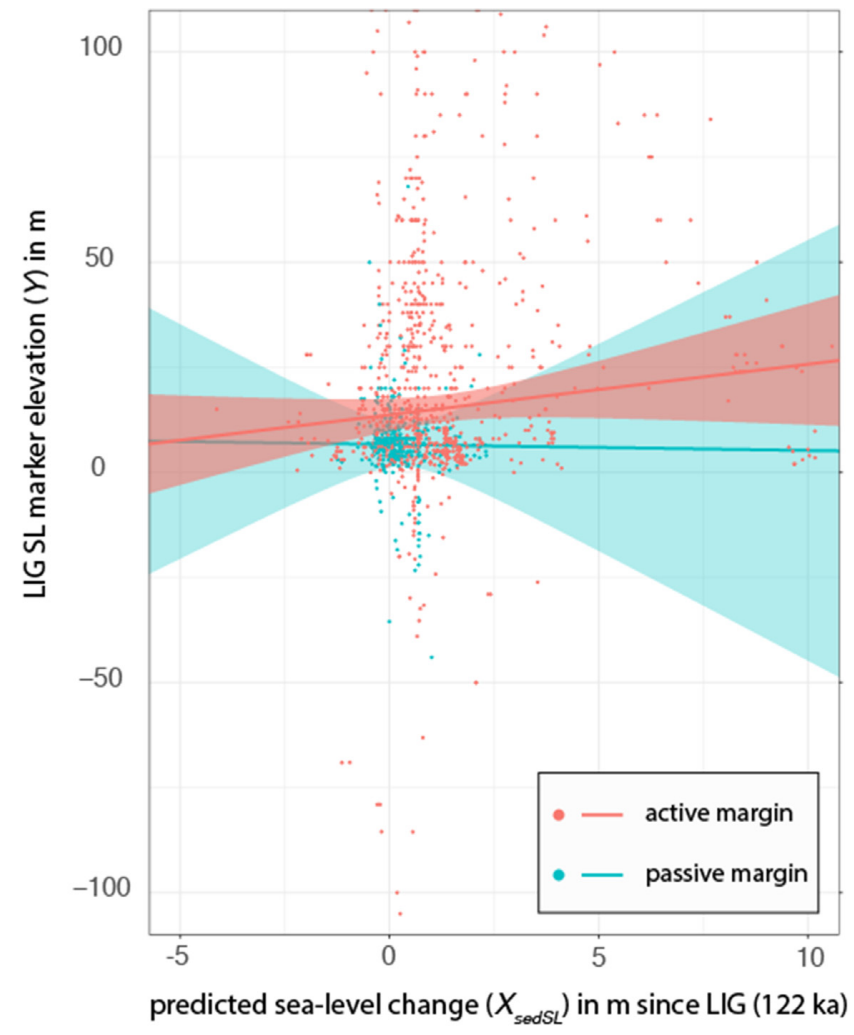

Figure 5. Correlation between predicted sea level change due to sediment loading $\left(X_{\text {SLsed }}\right)$ and the observed elevation of LIG sea level markers (active sites - pink dots; passive sites_-blue dots). Shaded regions represent error bars on each regression. For active margin sites there is a weak positive relationship, while for passive margin sites there is no relationship between predicted sea level change due to sediment loading and LIG sea level marker elevation.

By analysing the interaction term, we also determine that the slope describing the relationship between marker elevation and predicted sea level for sites on active margins is significantly ( 95 per cent confidence level) different $(\beta=1.307 \pm 0.434 ; p=0.00265)$ than the slope for passive margins.

We performed analyses with the upper and lower bound elevations of LIG sea level markers and found that the relationship between predicted sea level and observed LIG sea level markers was unchanged (Tables A2-A3). We also performed sensitivity tests where we altered the lithospheric thickness, and upper and lower mantle viscosity while retaining the sedimentation history in Fig. 2. Although using these different Earth models resulted in significant 
variability in the predicted sea level change (sometimes of opposite magnitude), our statistical analysis similarly found that the calculated correlation coefficients defined the same relationship between predicted sea level and LIG observations (Tables A4-A8). This insensitivity may reflect that a large fraction of locations for LIG sea level markers are far away from locations of sediment loads.

\section{DISCUSSION}

We have explored the impact of sediment loading on sea level over the last glacial cycle by: (1) generating a pattern of sediment deposition using a model of river delta evolution since the LIG and adopting modern day river sediment fluxes and (2) running a gravitationally self-consistent sea level solver simulating glacial isostatic adjustment.

A statistical analysis indicates that our predictions of sea level change due to sediment loading do not correlate strongly with the observed elevation of 1287 LIG sea level markers. At active margins, there is a statistically significant positive relationship between elevation and predicted sea level, whereas simple physical arguments suggest that the correlation should be negative. This positive correlation likely reflects the dominance of tectonic uplift at these sites because rates of uplift are not explicitly accounted for in our model. Though estimates of tectonic uplift exist at many sites, these estimates are largely based on the same LIG sea level markers, and using them would introduce circularity in our analysis.

Given the current LIG database and modelled sedimentation history, we cannot detect a globally coherent trend for the influence of sediment loading on LIG sea level. Future improvements in this data set, as well as detailed reconstructions of regional sedimentation histories, may ultimately reveal a signal of sediment loading on the elevation of LIG sea level markers. However, we note that the accuracy of our model predictions is limited by our assumption of a constant sediment flux and our method of constructing the geometry of deposition. Finally, while we have not detected global coherency between the predicted sediment loading signal and observations, the impact of such loading may nevertheless be important at passive margin sites (our estimates range from -1.24 to $16.27 \mathrm{~m}$ ) where the elevation of LIG sea level markers have been measured. This signal should thus be accounted for before these data sets are used, for example, to infer peak global mean sea level during the LIG.

\section{Implications for derived tectonic uplift rates in western United States/Barbados}

Since sediment loading effects can be significant locally at active tectonic margins, this contribution should be accounted for in estimating tectonic uplift rates based on the elevation of LIG sea level markers. Along the Pacific coast of the United States, sea level at some sites is perturbed by up to $10 \mathrm{~m}$ due to sediment loading (Fig. 6), comparable in magnitude (but opposite sign) to the impact of GIA since the LIG (8-14 m; Simms et al. 2015). We have recalculated the GIA-corrected tectonic uplift rates published in Simms et al. (2015) using the predictions described above to correct for sediment loading and find that doing so can decrease the predicted tectonic uplift rates at these sites by as much as 16 per cent (Table A10).

The tectonic uplift rate at Barbados has been estimated from the elevation of MIS6-5 sea level markers (Fairbanks 1989) by assuming that peak global mean sea level reached $6 \mathrm{~m}$ during the LIG (Radtke et al. 2006). This uplift rate has subsequently been used to correct (a)

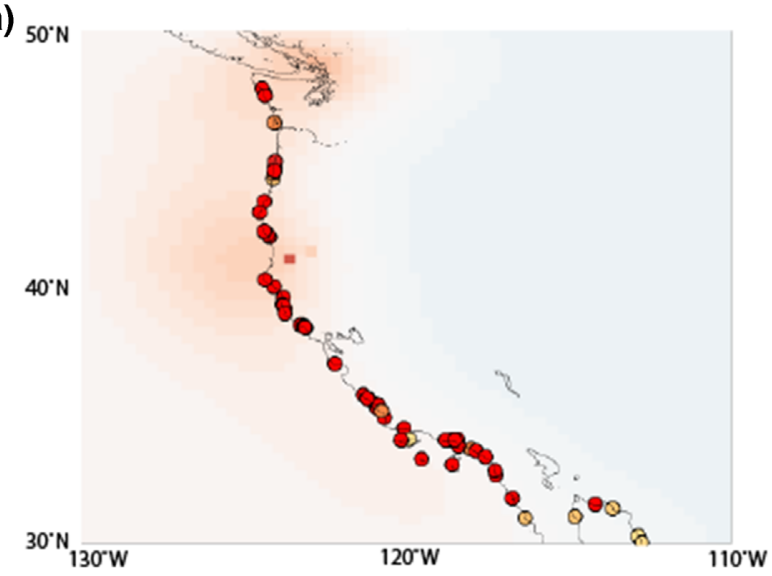

(b)

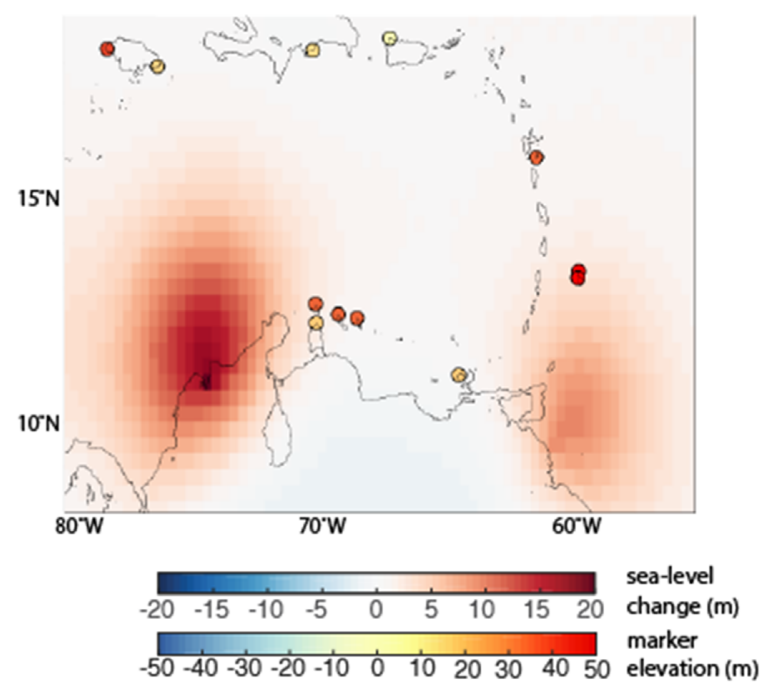

Figure 6. Predicted sea level change due to sediment loading since the LIG (as in Fig. 3) for the Pacific coast of the United States (a) and the Southern Caribbean (b). Sea level marker location and elevation shown by filled circles.

sea level records in this region for tectonic effects, including the deglacial sea level portion of the record which is widely used as a global ice volume curve in palaeoclimate, GIA, and ice modelling communities. At this site, we predict that sea level since the LIG has increased by $\sim 4$ m due to sediment loading (Fig. 6), and accounting for this signal increases the inferred tectonic uplift rate by $\sim 7$ per cent. We note that this systematic bias is in addition to the bias introduced by assuming that peak global mean sea level was $6 \mathrm{~m}$ and that local contamination of this peak due to GIA was insignificant (Creveling et al. 2015).

Revising tectonic uplift rates is important for our understanding of long-term tectonics in these regions. However, an accurate assessment of uplift rates is also important for estimating global mean sea level changes based on geological markers at these sites. Key sea level sites used in this effort (Huon Peninsula, Barbados, Vanuatu) are within active tectonic margins, in part because they have the potential to preserve shoreline features through uplift (Chappell et al. 1996; Cabioch \& Ayliffe 2001; Radtke et al. 2006). It is essential to consider the impact of sediment loading on sea level in these regions because sites of tectonic uplift are often associated with high rates of marine sedimentation. Indeed, accurate reconstructions of 
LIG sea level with the goal of determining long-term uplift rates becomes even more imperative when extrapolating these uplift rates to older shorelines, such as MIS 11 (Raymo \& Mitrovica 2012).

\section{CONCLUSION}

The elevation of LIG sea level markers is highly variable, and previous studies have not considered how the effects of sediment loading have influenced this variability on a global scale. We explore this variability by simulating deltaic deposition in 776 rivers over a full glacial cycle and computing the resulting sea level change due to sediment loading at 1287 sites in a database of LIG sea level markers. The analysis, based on a regression model that accounts for spatial autocorrelation and is robust to outliers, indicates that there is no statistically significant signal of sediment loading on the observed elevation of LIG sea level markers. This finding may result from limitations either in the sea level database or sediment modelling and may be obscured by uncertainties in glacial isostatic adjustment, tectonic uplift, or dynamic topography. Nevertheless, local changes in sea level due to sediment loading can be substantial close to large depositional centers and we show that accounting for this signal can bias inferred uplift rates in tectonically active regions such as Barbados and the North American Pacific coast. The statistical framework developed here can be used to assess the influence of processes that affect the vertical elevation of sea level markers, and will benefit future work aimed at improving regional predictions of sea level change due to sediment loading over the last glacial cycle.

\section{ACKNOWLEDGEMENTS}

A. Rovere and T. Lorscheid graciously shared the global database of LIG markers used in this study. S. Worthington at the Institute for Quantitative Social Sciences provided advice on statistical modelling. J. Mitrovica, J. Austermann, P. Huybers and K. Ferrier participated in insightful discussions, which improved the content of this manuscript. J. Weisenberg performed a literature review on this topic as an undergraduate researcher.

\section{REFER E N CES}

Austermann, J. et al., 2017. Detection of a dynamic topography signal in last interglacial sea level records, Sci. Adv, 3(7), e1700457.

Bahr, D.B. et al., 2001. Exponential approximations to compacted sediment porosity profiles, Comput. Geosci., 27(6), 691-700.

Cabioch, G. \& Ayliffe, L.K., 2001. Raised coral terraces at Malakula, Vanuatu, Southwest Pacific, indicate high sea level during marine isotope stage 3, Quat. Res., 56, 357-365.

Chappell, J., Ota, Y. \& Berryman, K., 1996. Late quaternary coseismic uplift history of Huon Peninsula, Papua New Guinea, Quat. Sci. Rev., 15(1), 7-22.

Creveling, J.R. et al., 2015. Revisiting tectonic corrections applied to Pleistocene sea level highstands, Quat. Sci. Rev., 111, 72-80.

Dalca, A.V. et al., 2013. On postglacial sea level-III. Incorporating sediment redistribution, Geophys. J. Int., 194(1), 45-60.

Dendy, S. et al., 2017. Sensitivity of last interglacial sea level high stands to ice sheet configuration during Marine Isotope Stage 6, Quat. Sci. Rev., 171, 234-244.

Dutton, A. \& Lambeck, K., 2012. Ice volume and sea level during the last interglacial, Science, 337(6091), 216-219.

Fagherazzi, S. \& Overeem, I., 2007. Models of deltaic and inner continental shelf landform evolution, Annu. Rev. Earth Planet. Sci., 35(1), 685-715.
Fairbanks, R.G., 1989. A 17,000 year glacio-eustatic sea level record: Influence of glacial melting rates on the Younger Dryas event and deep-ocean ciruclation, Nature, 342, 637-642.

Ferranti, L. et al., 2006. Markers of the last interglacial sea-level high stand along the coast of Italy : tectonic implications, Quat. Int., 146, 30-54.

Ferrier, K.L. et al., 2015. Sea-level responses to erosion and deposition of sediment in the Indus River basin and the Arabian Sea, Earth planet. Sci. Lett., 416, 12-20.

Ferrier, K.L. et al., 2018. The influence of water storage in marine sediment on sea-level change, Geophys. Res. Lett., 45(5), 2444-2454.

Hibbert, F.D. et al., 2016. Coral indicators of past sea-level change : a global repository of U-series dated benchmarks, Quat. Sci. Rev., 145, 1-56.

Johnston, P., 1993. The effect of spatially non-uniform water loads on prediction of sea-level change, Geophys. J. Int., 114(3), 615-634.

Kendall, R.A., Mitrovica, J.X. \& Milne, G.A. 2005. On post-glacial sea level - II. Numerical formulation and comparative results on spherically symmetric models, Geophys. J. Int., 161(3), 679-706.

Kopp, R.E. et al., 2009. Probabilistic assessment of sea level during the last interglacial stage, Nature, 462, 863-867.

Kopp, R.E. et al., 2013. A probabilistic assessment of sea level variations within the last interglacial stage, Geophys. J. Int., 193, 711-716.

Lambeck, K. et al., 2003. Water-load definition in the glacio-hydro-isostatic sea-level equation, Quat. Sci. Rev., 22(2-4), 309-318.

Lambeck, K. \& Chappell, J., 2001. Sea level change through the last glacial cycle, Science (New York, N.Y.), 292(5517), 679-686.

Milliman, J.D. \& Farnsworth, K.L., 2011. River Discharge to the Coastal Ocean: A Global Synthesis. Cambridge Univ. Press.

Milne, G.A. \& Mitrovica, J.X., 1996. Postglacial sea-level change on a rotating Earth: first results from a gravitationally self-consistent sea-level equation, Geophys. J. Int., 126(3), F13-F20.

Milne, G.A., Mitrovica, J.X. \& Davis, J.L., 1999. Near-field hydro-isostasy: the implementation of a revised sea-level equation, Geophys. J. Int., 139, 464-482.

Mitrovica, J.X. et al., 2005. The rotational stability of an ice-age earth, Geophys. J. Int., 161(2), 491-506.

Muhs, D.R. et al., 2012. Sea-level history during the last interglacial complex on San Nicolas Island, California: Implications for glacial isostatic adjustment processes, paleozoogeography and tectonics, Quat. Sci. Rev., 37, 1-25.

Pedoja, K. et al., 2014. Coastal staircase sequences reflecting sea-level oscillations and tectonic uplift during the Quaternary and Neogene, Earth Sci. Rev., 132, 13-38.

Peltier, W.R., Argus, D.F. \& Drummond, R., 2015. Space geodesy constrains ice age terminal deglaciation: the global ICE-6G_C (VM5a)model, $J$. geophys. Res., 120, 450-487.

Perron, J.T., 2017. Climate and the pace of erosional landscape evolution, Annu. Rev. Earth planet. Sci., 45(1), 561-591.

Pico, T. et al., 2016. Global ice volume during MIS 3 inferred from a sealevel analysis of sedimentary core records in the Yellow River Delta, Quat. Sci. Rev, 152, 72-79.

Pico, T., Creveling, J.R. \& Mitrovica, J.X. 2017. Sea-level records from the U.S. mid-Atlantic constrain Laurentide Ice Sheet extent during Marine Isotope Stage 3, Nat. Commun., 8(May), 15612. doi: 10.1038/ncomms15612.

Radtke, U. et al., 2006. Uplift history along the clermont nose traverse on the West Coast of Barbados during the Last 500,000 years-implications for Paleo-Sea level reconstructions stable, J. Coastal Res., 22(2), 350-360.

Raymo, M.E. \& Mitrovica, J.X. 2012. Collapse of polar ice sheets during the stage 11 interglacial, Nature, 483(7390), 453-456.

Simms, A.R. et al., 2007. Sea-level history of the Gulf of Mexico since the Last Glacial Maximum with implications for the melting history of the Laurentide Ice Sheet, Quat. Sci. Rev., 26, 920-940.

Simms, A.R. et al., 2013. Quantifying rates of coastal subsidence since the last interglacial and the role of sediment loading, Global Planet. Change, 111, 296-308.

Simms, A.R. et al., 2016. Marine terraces and rates of vertical tectonic motion : the importance of glacio-isostatic adjustment along the Pacific coast of central North America, Bull. geol. Soc. Am., 128(1-2), 81-93. 
Susanti, Y. et al., 2014. M estimation, S estimation, and MM estimation in robust regression, Int. J. Pure appl. Math., 91(3), 349-360.

Swenson, J.B., 2005. Fluvial and marine controls on combined subaerial and subaqueous delta progradation: Morphodynamic modeling of compoundclinoform development, J. geophys. Res., 110(F2), F02013.

Waelbroeck, C. et al., 2002. Sea-level and deep water temperature changes derived from benthic foraminifera isotopic records, Quat. Sci. Rev., 21(13), 295-305.

Wolstencroft, M. Shen, Z., Törnqvist, T. E., Milne, G. A. \& Kulp, M., 2014. Understanding subsidence in the Mississippi Delta region due to sediment, ice, and ocean loading: Insights from geophysical modeling, $J$. geophys. Res., 119(4), 3838-3856.

\section{APPENDIX}

\section{Accounting for glacial isostatic adjustment signal}

In the regression model we construct variable $\mathrm{X}_{\mathrm{GIA}}$ to account for the change in vertical elevation due to glacial isostatic adjustment since the LIG. We calculate this variable by averaging the value predicted at the LIG sea level marker sites for 70 GIA models, characterized by the thickness of the elastic lithosphere, and the viscosity of the upper and lower mantle. These three parameters were, respectively, varied over the following ranges: 71-96 km, 2$5 \times 10^{20} \mathrm{~Pa} \mathrm{~s}$ and $3-50 \times 10^{21} \mathrm{~Pa} \mathrm{~s}$. To construct a two-cycle ice history, we adopted the ICE-6 G model (Peltier et al. 2015) for both the last and penultimate deglacial period, and the glaciation phase in each cycle was modelled to follow the eustatic curve inferred by Waelbroeck et al. (2002). The ice history does not include excess melt (i.e. melting more than present day ice volumes) at the LIG.

\section{Sensitivity to uncertainty in sea level marker elevation}

We assessed the sensitivity of our resulting regression coefficients to the upper and lower uncertainty bounds associated with the LIG sea level marker database. We performed an analysis where we adopted the upper bound (observed marker elevation + indicative range), and found that the resulting $\beta$ coefficients similarly showed there is not a statistically significant relationship between predicted sediment loading and observed elevation of LIG sea level marker (Table A2). For the lower bound case (observed marker elevation - indicative range), we found a similar relationship (Table A3).

\section{Sensitivity to selection of Earth structure model}

Because the impact of sediment loading on sea level on ice-age timescales is dependent on the viscoelastic response of the solid Earth, we explored the sensitivity of our results using a range of Earth structure parameters (Tables A4-A8). We performed calculations using Earth structure models characterized by the following lithospheric thickness, and upper and lower mantle viscosities: $48 \mathrm{~km}, 0.5 \times 10^{21} \mathrm{~Pa} \mathrm{~s}, 15 \times 10^{21} \mathrm{~Pa} \mathrm{~s} ; 48 \mathrm{~km}, 0.5 \times 10^{21} \mathrm{~Pa} \mathrm{~s}$, $5 \times 10^{21} \mathrm{~Pa} \mathrm{~s}, 72 \mathrm{~km}, 0.5 \times 10^{21} \mathrm{~Pa} \mathrm{~s}, 15 \times 10^{21} \mathrm{~Pa} \mathrm{~s}$. We also tested the impact of sediment loading on sea level in the fluid case, assuming no elastic effects (only viscous), in order to understand the sea level change produced if sediment loads reached isostatic equilibrium. We found that these variations resulted in the same relationship between predicted sea level and observed LIG sea level marker elevations.

Table A1. Coefficients for main text analysis (Fig. 5).

\begin{tabular}{lrcrc}
\hline Main text results & $\beta$ Estimate & Std. Error & $t$ value & $\operatorname{Pr}(>|\mathrm{t}|)$ \\
\hline (Intercept) & 7.095 & 0.459 & 15.475 & $<2 \mathrm{e}-16$ \\
$X_{\text {SLsed }}$ & -0.138 & 0.305 & -0.453 & 0.651 \\
$X_{\text {active }}$ & 8.344 & 1.090 & 7.658 & $3.72 \mathrm{E}-14$ \\
$X_{\text {GIA }}$ & -1.102 & 0.453 & -2.433 & 0.0151 \\
$X_{\text {autocovariate }}$ & 0.028 & 0.004 & 6.459 & $1.49 \mathrm{E}-10$ \\
$X_{\text {interact }}$ & 1.307 & 0.434 & 3.011 & 0.00265 \\
Adjusted $R^{2}$ & 0.164 & & & \\
\hline
\end{tabular}

Table A2. Upper bound.

\begin{tabular}{lccrc}
\hline Upper bound results & $\beta$ Estimate & Std. Error & $t$ value & $\operatorname{Pr}(>|\mathrm{t}|)$ \\
\hline (Intercept) & 9.176 & 0.525 & 17.481 & $<2 \mathrm{e}-16$ \\
$X_{\text {SLsed }}$ & -0.238 & 0.356 & -0.667 & 0.50508 \\
$X_{\text {active }}$ & 9.495 & 1.092 & 8.695 & $<2 \mathrm{e}-16$ \\
$X_{\text {GIA }}$ & -1.141 & 0.490 & -2.328 & 0.02007 \\
$X_{\text {autocovariate }}$ & 0.030 & 0.004 & 7.203 & $1.00 \mathrm{E}-12$ \\
$X_{\text {interact }}$ & 1.504 & 0.496 & 3.035 & 0.00245 \\
Adjusted $R^{2}$ & 0.156 & & & \\
\hline
\end{tabular}


Table A3. Lower bound.

\begin{tabular}{lcccc}
\hline Lower bound results & $\beta$ Estimate & Std. Error & $t$ value & $\operatorname{Pr}(>|t|)$ \\
\hline (Intercept) & 4.987 & 0.467 & 10.668 & $<2 \mathrm{e}-16$ \\
$X_{\text {SLsed }}$ & -0.090 & 0.304 & -0.297 & 0.7668 \\
$X_{\text {active }}$ & 8.545 & 1.041 & 8.207 & $5.48 \mathrm{E}-16$ \\
$X_{\text {GIA }}$ & -1.136 & 0.445 & -2.555 & 0.0107 \\
$X_{\text {autocovariate }}$ & 0.029 & 0.005 & 6.205 & $7.38 \mathrm{E}-10$ \\
$X_{\text {interact }}$ & 0.972 & 0.406 & 2.395 & 0.0168 \\
Adjusted $R^{2}$ & 0.158 & & & \\
\hline
\end{tabular}

Tables A4-A8. Earth model variations.

\begin{tabular}{|c|c|c|c|c|}
\hline VM2 fluid ln & Estimate & Std. Error & $t$ value & $\operatorname{Pr}(>|t|)$ \\
\hline$X_{\text {SLsed }}$ & -0.051 & 0.077 & -0.661 & 0.508669 \\
\hline$X_{\text {active }}$ & 5.664 & 1.193 & 4.747 & $2.30 \mathrm{E}-06$ \\
\hline$X_{\text {autocovariate }}$ & 0.028 & 0.004 & 6.327 & $3.44 \mathrm{E}-10$ \\
\hline$X_{\text {interact }}$ & -1.150 & 0.295 & -3.898 & 0.000102 \\
\hline Adjusted $R^{2}$ & 0.1648 & & & \\
\hline (Intercept) & 7.124 & 0.409 & 17.434 & $<2 \mathrm{e}-16$ \\
\hline$X_{\text {SLsed }}$ & -0.051 & 0.077 & -0.661 & 0.5088 \\
\hline$X_{\text {active }}$ & 5.606 & 1.197 & 4.683 & $3.13 \mathrm{E}-06$ \\
\hline$X_{\mathrm{GIA}}$ & -1.032 & 0.443 & -2.328 & 0.0201 \\
\hline$X_{\text {autocovariate }}$ & 0.028 & 0.004 & 6.334 & $3.31 \mathrm{E}-10$ \\
\hline$X_{\text {interact }}$ & -1.153 & 0.295 & -3.908 & $9.81 \mathrm{E}-05$ \\
\hline$X_{\text {active }}$ & 5.531 & 1.208 & 4.578 & $5.15 \mathrm{E}-06$ \\
\hline$X_{\mathrm{GIA}}$ & -1.033 & 0.444 & -2.329 & 0.02 \\
\hline$X_{\text {autocovariate }}$ & 0.028 & 0.004 & 6.334 & $3.30 \mathrm{E}-10$ \\
\hline$X_{\text {interact }}$ & -1.152 & 0.295 & -3.906 & $9.87 \mathrm{E}-05$ \\
\hline Adjusted $R^{2}$ & 0.1646 & & & \\
\hline 48p515 & Estimate & Std. Error & $t$ value & $\operatorname{Pr}(>|t|)$ \\
\hline (Intercept) & 7.125 & 0.409 & 17.413 & $<2 \mathrm{e}-16$ \\
\hline$X_{\text {SLsed }}$ & -0.051 & 0.077 & -0.661 & 0.508669 \\
\hline$X_{\text {active }}$ & 5.609 & 1.200 & 4.674 & $3.27 \mathrm{E}-06$ \\
\hline$X_{\mathrm{GIA}}$ & -1.037 & 0.444 & -2.336 & 0.019638 \\
\hline$X_{\text {autocovariate }}$ & 0.028 & 0.004 & 6.327 & $3.44 \mathrm{E}-10$ \\
\hline$X_{\text {interact }}$ & -1.150 & 0.295 & -3.898 & 0.000102 \\
\hline
\end{tabular}


Table A9. Effect of sediment loading sea level change on inferred tectonic uplift rates on west coast of United States.

\begin{tabular}{|c|c|c|c|c|c|}
\hline Latitude & Longitude & $\begin{array}{l}\text { LIG terrace elevation } \\
\qquad(\mathrm{m})\end{array}$ & $\begin{array}{l}\text { Inferred uplift rate in } \\
\text { Simms et al. }\left(\mathrm{m} \mathrm{ky}^{-1}\right)\end{array}$ & $\begin{array}{l}\text { Updated uplift rate } \\
(\text { sediment load } \\
\text { correction) }\left(\mathrm{m} \mathrm{ky}^{-1}\right)\end{array}$ & $\begin{array}{l}\text { Change in uplift } \\
\text { rate (per cent) }\end{array}$ \\
\hline 44.63 & 124.05 & 109 & 0.82 & 0.84 & 2.69 \\
\hline 43.69 & 124.39 & 98 & 0.72 & 0.74 & 3.31 \\
\hline 43.12 & 124.42 & 105 & 0.78 & 0.81 & 3.26 \\
\hline 42.05 & 124.28 & 111 & 0.83 & 0.86 & 3.45 \\
\hline 39.61 & 123.79 & 40 & 0.23 & 0.24 & 4.61 \\
\hline 37.9 & 122.69 & 142 & 1.08 & 1.09 & 0.61 \\
\hline 36.96 & 122.09 & 170 & 1.32 & 1.38 & 4.74 \\
\hline 35.64 & 121.19 & 25 & 0.1 & 0.11 & 8.34 \\
\hline 35.45 & 120.95 & 7 & -0.05 & -0.04 & -16.25 \\
\hline 35.26 & 120.9 & 30 & 0.14 & 0.15 & 6.29 \\
\hline 34.47 & 120.23 & 35 & 0.19 & 0.20 & 4.92 \\
\hline 33.96 & 119.71 & 5 & -0.07 & -0.06 & -14.43 \\
\hline 33.96 & 120.05 & 24 & 0.09 & 0.10 & 12.24 \\
\hline 34.02 & 120.33 & 22.5 & 0.08 & 0.09 & 14.34 \\
\hline 34.03 & 118.71 & 58 & 0.38 & 0.39 & 1.50 \\
\hline 33.74 & 118.28 & 75 & 0.52 & 0.53 & 1.00 \\
\hline 33.61 & 117.86 & 34 & 0.18 & 0.18 & 2.02 \\
\hline 33.25 & 119.48 & 36 & 0.19 & 0.20 & 5.94 \\
\hline 32.93 & 118.54 & 31 & 0.15 & 0.16 & 5.98 \\
\hline 33.17 & 117.35 & 22 & 0.08 & 0.08 & 3.77 \\
\hline 32.67 & 117.24 & 23 & 0.09 & 0.09 & 4.21 \\
\hline 31.74 & 116.74 & 35.5 & 0.19 & 0.19 & 1.69 \\
\hline 31.33 & 116.44 & 17 & 0.04 & 0.04 & 5.72 \\
\hline 27.69 & 114.86 & 22.5 & 0.12 & 0.12 & 2.34 \\
\hline
\end{tabular}

Table A10. Effect of sediment loading sea level change on inferred tectonic uplift rates in Barbados.

\begin{tabular}{lccccc}
\hline Latitude & Longitude & $\begin{array}{c}\text { LIG terrace elevation } \\
(\mathrm{m})\end{array}$ & $\begin{array}{c}\text { Inferred uplift rate in } \\
\text { Creveling } \text { et al. }(\mathrm{m} \\
\left.\mathrm{ky}^{-1}\right)\end{array}$ & $\begin{array}{c}\text { Updated uplift rate } \\
\text { (sediment load } \\
\text { correction) }\left(\mathrm{m} \mathrm{ky}^{-1}\right)\end{array}$ & $\begin{array}{c}\text { Change in uplift } \\
\text { rate (per cent) }\end{array}$ \\
\hline 13.1330 & 59.6330 & 60.0000 & 0.4805 & 0.5279 & 6.5626 \\
13.1380 & 59.6310 & 60.0000 & 0.4805 & 0.5278 & 6.5445 \\
13.1400 & 59.6340 & 60.0000 & 0.4156 & 0.4566 & 6.5379 \\
\hline
\end{tabular}

